\title{
A Case of Anti-N-Methyl-D-Aspartate Receptor Encephalitis Associated with Glioma of the Pons
}

\author{
Francesca Beretta $a^{a, b}$ \\ Angelo Aliprandi ${ }^{b}$ \\ Claudio Di Leo ${ }^{\mathrm{C}}$ \\ Andrea Salmaggi ${ }^{b}$ \\ Università degli Studi di Milano-Bicocca- \\ School of Neurology, Milano, Italy \\ bepartments of Neurology and \\ 'Nuclear Medicine, ASST Lecco, Lecco, \\ Italy
}

Received May 28, 2018

Revised August 11, 2018

Accepted August 13, 2018

\section{Correspondence}

Francesca Beretta, MD

Department of Neurology, ASST Lecco, Via Dell'Eremo 9/11, 23900 Lecco, Italy

Tel +39-0341-489805

Fax +39-0341-489801

E-mail franci.beretta@hotmail.com
Dear Editor,

Anti-N-Methyl-D-Aspartate-receptor (NMDAR) encephalitis is a recently described disease with an autoimmune pathological basis often paraneoplastic in origin. Herein we present a case of anti-NMDAR encephalitis in a young woman characterized by the unusual association with brain glioma.

Our patient was a 32-year-old woman known to our department through previous hospitalizations. She had received surgery due to severe head trauma at the age of 26 years, and 3 years later (in July 2012) she had been diagnosed a low-grade glioma of the pons (pilocytic astrocytoma). Concurrent pregnancy meant that surgical treatment consisting of partial resection was not performed until July 2013. A cycle of targeted radiotherapy was performed after finding evidence of progression, and amounted to 56 Gy subdivided in 28 fractions of 2 Gy each; this treatment was completed in June 2014.

In October 2014 our patient started experiencing episodes of agitation and aggressiveness associated with visual hallucinations, paranoid delusions, and deficits of working memory. One month later she developed recurrent generalized tonic-clonic seizures resistant to multiple therapies, and, consequently, required hospitalization. It was particularly notable that the interictal electroencephalogram showed generalized bisynchronous slow activity suggestive of an underlying encephalopathy in the absence of epileptiform activity. Therapy with valproate, carbamazepine, levetiracetam, lorazepam, and lacosamide was not effective, and her level of consciousness worsened, reaching severe coma within a few days.

Brain computed tomography (CT) and magnetic resonance imaging (MRI) produced negative findings, her thyroid function was normal, and an analysis of cerebrospinal fluid (CSF)—including testing for neurotropic pathogens and neoplastic cells-produced normal results. Based on the hypothesis of an autoimmune encephalitic process, and in particular anti-NMDAR encephalitis, onconeuronal antibodies were searched for. Ri, Yo, and Hu tested negative (both serum and CSF), while IgG antibodies against the GluN1 NMDAR subunit tested positive in both serum and CSF. Thus, treatment with high-dose intravenous corticosteroids (methylprednisolone at $1 \mathrm{~g}$ daily for 5 days) and intravenous immunoglobulins (three cycles) was initiated.

This intervention resulted in an initial improvement in mental status and a reduction in the number of seizures. However, complete recovery was not achieved, with the patient alternating between periods of awareness during which she was able to interact with relatives and medical personnel, and periods of psychomotor agitation during which she also exhibited orofacial and limb dyskinesias as well as choreoathetosis.

An extensive diagnostic workup that included a total-body CT scan and ${ }^{18} \mathrm{~F}$-fluorodeoxyglucose positron emission tomography $\left({ }^{18} \mathrm{~F}-\mathrm{FDG}-\mathrm{PET}\right)$ excluded the presence of an underlying neoplasm, and specifically of ovarian teratoma. It was particularly notable that brain ${ }^{18}$ F-FDG-PET/CT showed severe hypometabolism in the occipital cortex bilaterally and re-

@ This is an Open Access article distributed under the terms of the Creative Commons Attribution Non-Commercial License (https://creativecommons.org/licenses/by-nc/4.0) which permits unrestricted non-commercial use, distribution, and reproduction in any medium, provided the original work is properly cited. 
duced tracer uptake in the basal ganglia (Fig. 1).

In February 2015 she started experiencing sudden-onset respiratory crises characterized by severe hypoventilation. She was treated initially with four cycles of rituximab and two cycles of cyclophosphamide, which produced no benefit, and subsequently with four cycles of plasma exchange (each one consisting of 5 sessions), which produced a modest improvement in her mental status only. Prophylactic bilateral salpingooophorectomy was also performed, and a histopathological examination of ovarian tissue produced normal findings. Follow-up brain ${ }^{18} \mathrm{~F}$-FDG-PET/CT appeared to indicate remission, while brain MRI showed a minimal increase in the size of the residual glioma (Fig. 1). In December 2015, following a particularly severe respiratory crisis, she entered a severe unremitting coma and died shortly afterwards. An autopsy was not performed.

As previously stated, anti-NMDAR encephalitis is a recently described disease with an autoimmune pathological basis. The binding of autoantibodies to the GluN1 NMDAR subunit, with consequent receptor internalization and inhibition, has been proposed as the underlying pathogenic mechanism. ${ }^{1}$ The presentation usually follows a subacute course, with the development of behavioral abnormalities or psychiatric symptoms that are often associated with short-term memory impairment and altered mental status. ${ }^{2,3}$ The results of imaging findings and of CSF examination are often unremarkable, although
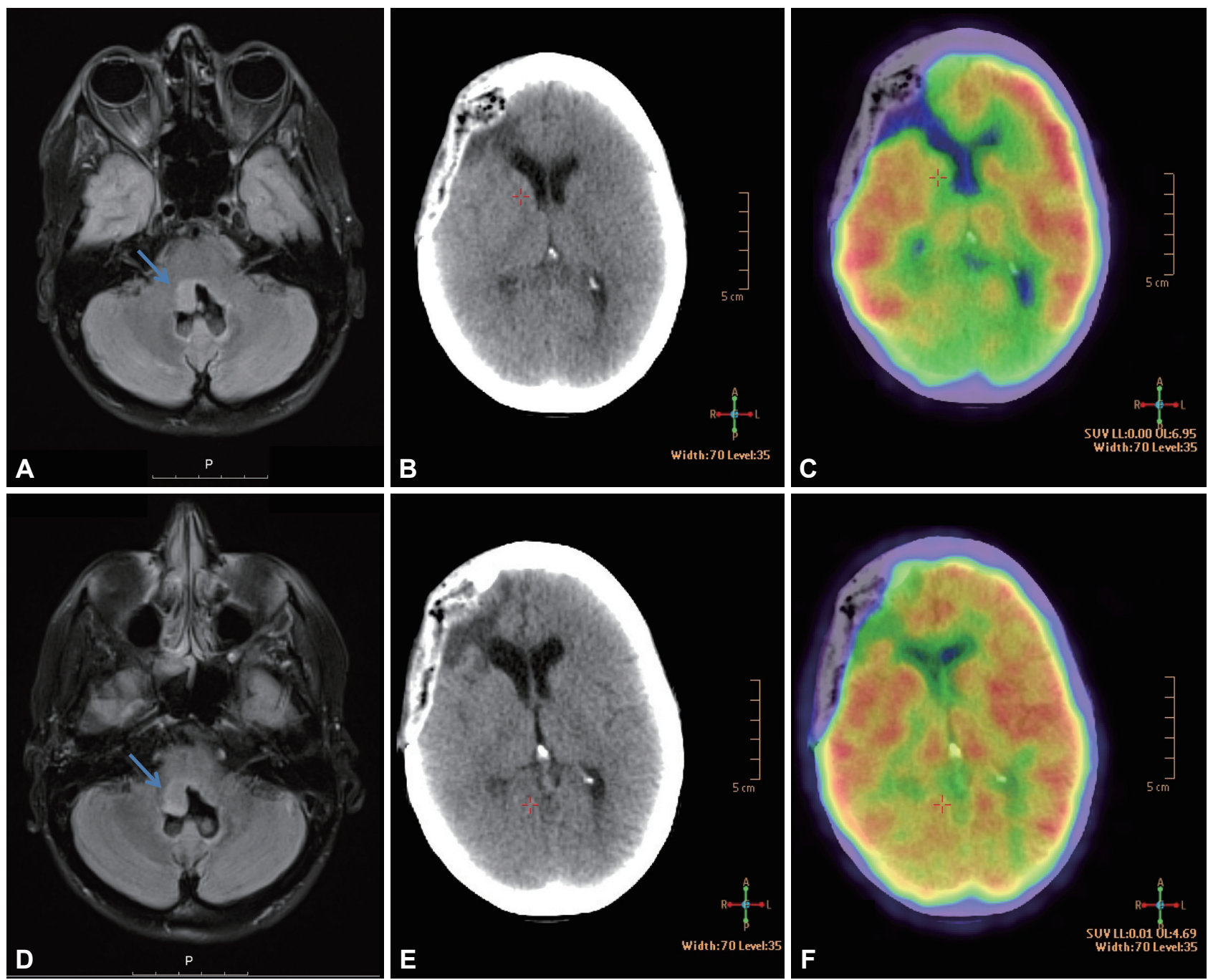

Fig. 1. MRI and ${ }^{18} \mathrm{~F}$-FDG-PET/CT images obtained at the onset of anti-NMDA-receptor encephalitis $(A, B$, and $C)$ and after relapse (D, E, and F). FLAIR axial images obtained at disease onset $(A)$ and control obtained several months after relapse (D). The residual glioma (arrows) can be seen extending into the fourth ventricle in both images (A and D), with a minimal increase in size and a signal hyperintensity evident in the second one. B and $C$ : ${ }^{18} \mathrm{~F}$ FDG-PET/CT images obtained at disease onset, which show severe hypometabolism in the occipital regions and reduced tracer uptake in the basal ganglia. E and F: ${ }^{18} \mathrm{~F}-\mathrm{FDG}-\mathrm{PET} / \mathrm{CT}$ images obtained after relapse, showing an uneven distribution of the tracer but no specific hypometabolic area. Signs of previously operated frontal head trauma are evident in both ${ }^{18} \mathrm{~F}$-FDG-PET/CT images. CT: computed tomography, ${ }^{18} \mathrm{~F}-\mathrm{FDG}$ : ${ }^{18} \mathrm{~F}-\mathrm{fluorodeoxyglucose}$, FLAIR: fluidattenuated inversion recovery, MRI: magnetic resonance imaging, NMDA: N-Methyl-D-Aspartate, PET: positron emission tomography. 
bolic standpoint, the clinical status of our patient continued to worsen. Since ${ }^{18} \mathrm{~F}-\mathrm{FDG}$-PET is an expensive diagnostic modality that is not widely available, further research is needed to better delineate its possible role in the diagnosis of autoimmune encephalitis.

\section{Conflicts of Interest}

The authors have no financial conflicts of interest.

\section{REFERENCES}

1. Dalmau J, Lancaster E, Martinez-Hernandez E, Rosenfeld MR, BaliceGordon R. Clinical experience and laboratory investigations in patients with anti-NMDAR encephalitis. Lancet Neurol 2011;10:63-74.

2. Liu CY, Zhu J, Zheng XY, Ma C, Wang X. Anti-N-methyl-D-aspartate receptor encephalitis: a severe, potentially reversible autoimmune encephalitis. Mediators Inflamm 2017;2017:6361479.

3. Graus F, Titulaer MJ, Balu R, Benseler S, Bien CG, Cellucci T, et al. A clinical approach to diagnosis of autoimmune encephalitis. Lancet Neurol 2016;15:391-404.

4. Palygin O, Lalo U, Pankratov Y. Distinct pharmacological and functional properties of NMDA receptors in mouse cortical astrocytes. $\mathrm{Br}$ J Pharmacol 2011;163:1755-1766.

5. Probasco JC, Solnes L, Nalluri A, Cohen J, Jones KM, Zan E, et al. Decreased occipital lobe metabolism by FDG-PET/CT: an anti-NMDA receptor encephalitis biomarker. Neurol Neuroimmunol Neuroinflamm 2017;5:e413.

6. Tripathi M, Tripathi M, Roy SG, Parida GK, Ihtisham K, Dash D, et al. Metabolic topography of autoimmune non-paraneoplastic encephalitis. Neuroradiology 2018;60:189-198. 